\title{
Descriptive Analysis of Acceptance by Prescribers and Economic Benefit of Pharmacist Recommended Interventions in a Critical Care Unit
}

YoonJung Lee, Pharm $D^{1,2}$; Lana Gettman, Pharm $D^{2}$

${ }^{1}$ Texas Tech University Health Sciences Center; ${ }^{2}$ Harding University College of Pharmacy

\begin{abstract}
Background: Pharmacist clinical intervention is defined as the action that identifies and prevents medication-related problems and optimizes patient's medication therapy in cooperation with other healthcare professionals. Types of clinical interventions may vary, but each is patient specific. Few studies have focused on clinical pharmacists interventions in a critical care setting at a rural hospital. Objectives: The purpose of this study was to assess physician acceptance rate of pharmacist-recommended interventions in the critical care unit (CCU) at a rural hospital over five years and to evaluate the economic benefit of accepted pharmacist-recommended interventions over a one-year time period.

Methods: This study was a retrospective chart review over a five-year time period. Each intervention was categorized and analyzed for acceptance or non-acceptance by the treating physician. Evaluation of economic benefit, cost saving and cost avoidance, for a one-year time period was performed.

Results: A total of 1275 interventions were documented during study period. The average acceptance rate for documented interventions was 56\%. The acceptance rate by physicians increased over the study period; with the acceptance rate in 2013 being statistically significantly higher than any other years. The overall cost saving for selected interventions was $\$ 432$ for the one year. The overall cost avoidance of all accepted interventions for the one year was $\$ 453,339.36-\$ 468,327.62$.

Conclusion: Clinical pharmacists provide various types of interventions to improve patient care. The analysis of potential cost saving and cost avoidance of selected interventions illustrated a positive economic outcome.
\end{abstract}

Key words: pharmacist clinical interventions; prescriber acceptance; cost benefit analysis; critical care; clinical pharmacy service

\section{Introduction}

Pharmacist clinical intervention is defined as the action that identifies and prevents medication-related problems and optimizes patient's medication therapy in cooperation with other health-care professionals. ${ }^{1}$ According to the American Society of Health-System Pharmacists (ASHP) position statement on pharmaceutical care, "The pharmacist is personally accountable for patient outcomes that ensue from the pharmacist's actions and decisions. As an accountable member of the health-care team, the pharmacist must document the care provided."2 Types of clinical interventions may vary, but each is patient specific. The most commonly documented interventions made by pharmacists involved in patient care include: appropriate medication selection, dosage and/or interval adjustment, initiation or discontinuation of drug therapy, elimination of therapeutic duplication, addressing untreated indication, pharmacokinetic monitoring, medication education, and drug-drug interactions. ${ }^{1,3}$

Corresponding author: YoonJung Lee, PharmD, Graduate Student/Research Assistant at Texas Tech University Health Sciences Center, Amarillo, 1300 S. Coulter St, Amarillo, TX 79106; former student at the time of the project, Harding University College of Pharmacy, Box 12230, Searcy, AR 72149. Tel: 714-474-3819; Fax: 501-279-5202

E-mail: yoonjung.lee@ttuhsc.edu; ylee@harding.edu
Team-based direct patient care has been identified as vital to meet patient needs and to improve health-care outcomes. ${ }^{4}$ Furthermore, some studies concluded that coordinated care between physicians and pharmacists could improve patient care outcomes. ${ }^{5-8}$ In the position paper from American College of Clinical Pharmacy task force on critical care pharmacy services, clinical pharmacists in critical care units (CCU) are recognized as essential members of physician-led multidisciplinary team for the delivery of quality care to critically ill patients. ${ }^{9}$ Brilli et al. stated the importance of having a multidisciplinary model wherein dedicated intensive care unit (ICU) personnel, specifically the intensivist, the ICU nurse, respiratory care practitioner, and pharmacist, all work as a team. ${ }^{10}$ Clinical pharmacists are trained to provide direct patient care and to monitor medication therapy with the goal of achieving desired therapeutic outcomes and reducing adverse health events. Clinical pharmacists in ICU also offer expertise in nutritional support, cardiorespiratory resuscitation, clinical research, and comprehensive critical care. $^{9}$

A meta-analysis of 298 studies in inpatient and outpatient pharmacy settings demonstrated that pharmacist-provided patient care resulted in positive clinical outcomes through enhanced disease management. ${ }^{11}$ Pharmacist-recommended interventions in a critical care setting decreased the rate of preventable adverse drug events (ADEs) by 66\%. ${ }^{12}$ A $70 \%$ 
reduction of preventable adverse drug events have been reported when pharmacists participated in the hospital rounding team. ${ }^{13} \mathrm{Few}$ studies have focused on the economic benefit of clinical pharmacist interventions in a critical care setting. Kopp et al. evaluated clinical interventions of a critical care pharmacist in a surgical intensive care unit over four and half months. ${ }^{14}$ of 129 total clinical interventions, a positive economic outcome due to potential cost avoidance ranged between $\$ 205,919$ and $\$ 280,421$. Possible cost avoidance was estimated based on the following formula: probability of adverse drug events $\times \$ 6,395 \times$ number of interventions. ${ }^{14} \mathrm{Kopp}$ et al. calculated $\$ 6,395$ by inflating $\$ 4,685$, original value reported in the Bate's article in 1997, using Consumer Price Index for the cost of preventable ADE. ${ }^{14}$ The authors of this study also identified chart review and medical rounds as two major clinical activities that are associated with the highest number of interventions and the greatest potential for cost avoidance.

In 2013, American Society of Health-System Pharmacists conducted a national survey which focused on pharmacy practice in hospital setting in the United States. The results showed that the majority (83.9\%) of hospitals collected information about type, frequency, and acceptance of interventions. However, less than half of surveyed hospitals analyzed the data for cost savings (49.6\%). Also, the study did not focus on the critical care setting in hospitals located in rural areas. Less than one-third of hospitals (127 out of $414,30.7 \%$ ) in the survey were located outside of the metropolitan statistical area. ${ }^{15}$

Despite $90 \%$ of the United States land mass being rural and $20 \%$ of Americans living in rural areas, only $12 \%$ of pharmacists practice in rural locations, indicating the need to address the shortage of clinical pharmacy services in the rural areas. ${ }^{16}$

White County Medical Center/Unity Health is the 438-bed community hospital providing service to six-county rural areas in Arkansas. Before our study, the hospital did not offer any clinical pharmacy services. Over a period of time, new clinical pharmacy service was successfully implemented in the critical care unit. The purpose of our study was to assess physician acceptance rate of pharmacist-recommended interventions in the critical care unit at White County Medical Center/Unity Health in Arkansas, during the 5-year period following implementation of a new clinical pharmacist service, and to evaluate economic benefit of accepted pharmacistrecommended selected interventions over one-year duration.

\section{METHODS}

\section{Setting}

Harding University College of Pharmacy (HUCOP) collaborated with White County Medical Center/Unity Health to establish new clinical pharmacy service in the critical care unit. Before
August 2008, the hospital had centralized pharmacy drug distribution; however, clinical pharmacy services did not exist. A faculty preceptor, who is a licensed pharmacist, initiated clinical interventions/services to improve patient care by communicating mostly in writing and occasionally verbally with physicians. Documented interventions from August 1, 2008, to December 31, 2013, were de-identified and included in this study. The study was approved by the Harding University Institutional Review Board (IRB) for Human Subjects and by the White County Medical Center/Unity Health Physician Review Committee.

\section{Data Collection}

During the study period, one HUCOP faculty member dedicated to the unit provided clinical recommendation to CCU physicians. Also, under the preceptor's direct supervision, fourth-year students on advanced pharmacy practice experience (APPE) in the CCU provided recommendations. During the first five years of faculty collaboration with the CCU, the hospital did not have a rounding team. Therefore, the pharmacist communicated the majority of recommendations to physicians in a written format via designated form placed in patient charts. For urgent interventions, the pharmacist communicated with physicians by contacting via telephone or in person. Due to a software change in June 2011, interventions were electronically documented by the pharmacist using two separate software systems, initially CPSI hospital system and later MedMined program. Documented interventions in each system were evaluated by the same methodology and were recorded and reported together in this study.

\section{Data Analysis}

Review and analysis of intervention records began in January 2013 and concluded in July 2014. To identify pre-existing classification system for drug related problems (DRP) and pharmacist intervention categories, a literature search was conducted in PubMed using the following search terms: "drug related problem classification systems" and "pharmacist intervention classification systems". Selected classification systems from the literature search include: American Society of Hospital Pharmacists (ASHP) classification, national coordinating council for medication error reporting and prevention (NCC-MERP) taxonomy of medication errors, Westerlund system, and Pharmaceutical Care Network Europe (PCNE) system. ${ }^{17-20}$ After review of these classification systems, interventions performed in the CCU were assigned into the following eight categories: toxicity/adverse drug reactions (ADRs), education, monitoring, drug selection, undertreated, over or underdose, compliance with hospital protocols, and not classifiable. 'Not classifiable' category included interventions which did not fit into other seven categories. Each intervention was classified by the type and then further defined as accepted or rejected by the treating physician. Pharmacistrecommended interventions implemented by the physician 
within 72 hours were defined as accepted interventions. Both electronic and paper medical records were evaluated to determine if a recommendation was accepted.

Evaluation of the potential cost saving and cost avoidance was performed by analyzing interventions between January 1, 2013, and December 31, 2013, the year with the highest acceptance rate. Cost saving is defined as the difference between the cost of the initial therapy and the new therapy. ${ }^{21,22}$ Amount of cost saving was calculated based on average wholesale price (AWP) obtained from Lexicomp and Micromedex for each medication that was discontinued or when a dose reduction was recommended.

Cost avoidance is defined as prevention of additional medical resources utilization and drug misadventures/medication errors. ${ }^{21,22}$ Potential cost avoidance associated with pharmacist interventions was calculated by using evidence based information in the medical literature (Table 4). ${ }^{23-30}$ Similar to our study, several other studies evaluated medical literature to calculate cost avoidance per intervention. For example, Campbell et al. conducted a comprehensive MEDLINE search to identify several studies which evaluated cost avoidance for different types of clinical pharmacy interventions. ${ }^{31}$ Each study was reviewed to establish an average cost avoidance value for the types of clinical interventions performed. Similar method was used in the study by Shepler et al., in which cost saving and cost avoidance were calculated using the primary and tertiary literature sources. ${ }^{23,31}$

A literature search was conducted in PubMed and International Pharmaceutical Abstracts (IPA) databases from 2008 to 2014 using the following search terms: "cost of rhabdomyolysis management", "cost of methicillin-resistant Staphylococcus aureus management", "cost saving associated with prevention of allergic reaction", "cost of hyperglycemia management", "cost of gastrointestinal bleeding management", "cost of deep venous thrombosis management", "cost of sepsis management", and "cost of enoxaparin associated bleeding". Using the methodology adopted from Campbell's study, we used literature findings to estimate the cost avoidance for the selected types of interventions.

To estimate cost avoidance for accepted interventions for which either medical references and/or cost avoidance values were not available, the modified method adopted from the studies by Saokaew and Nesbit was used. ${ }^{32,33}$ For each pharmacist intervention lacking cost avoidance reference, an intervention was evaluated to estimate the probability of a preventable adverse event ( $\mathrm{ADE}$ ) occurring on the basis of the clinical details surrounding the intervention. During this process, judgment based on patient's clinical data was used to assign each intervention into one of the five probability categories. The probability of a preventable ADE in the absence of intervention was set as: (1) 0 (zero; e.g. information requested), (2) 0.01 (very low; for problem orders such as clarifications, missing information, nonexistent strengths), (3) 0.1 (low; for prevented a potentially significant reaction such as 2-4 $x$ normal dose, medication/dose inadequate to produce therapeutic effect; incorrect schedule/route with potential for therapeutic failure/toxicity; duplicate therapy with potential for additive toxicity), (4) 0.4 (medium; for prevented a potentially serious reaction e.g. allergy to drug ordered, no allergy information, 4-10 x normal dose; no adjustment of medication with renal failure or other issues such as hyperkalemia or elevated trough level), (5) 0.6 (high; for prevented a potentially fatal or severe reaction e.g. $10 \times$ normal dose; narrow therapeutic range; life-threatening reaction/anaphylaxis). ${ }^{32}$ To calculate the average cost of an $A D E$, the average cost of a preventable adverse event reported in Bate's study $(\$ 4,685)$ was inflated using the Consumer Price Index (CPI) from 2008 to $2013 .{ }^{33,34,35}$ Then, the average cost of an ADE was $\$ 7108.16$ to $\$ 7561.18$. Lastly, cost avoidance for each intervention was calculated by multiplying the estimated probability of an $A D E$ in the absence of the intervention with the average cost of an ADE. For example, a patient was receiving higher than indicated dose of vancomycin and had elevated vancomycin trough above 20 . In this case, the pharmacist recommended to hold vancomycin dose for a patient until the vancomycin trough level dropped below 20 . The pharmacist estimated the probability of an ADE, in the absence of the intervention, to be (4) 0.4 (medium). Therefore, the cost avoidance in this case was: 0.4 (probability of a preventable ADE ) $\times \$ 7108.16$ to $\$ 7561.18$ (inflated average cost of a preventable adverse event) $=\$ 2843.20$ to $\$ 3024.40$ This method was used to estimate cost avoidance for 91 accepted interventions that lacked medical references and/or cost avoidance value in the literature.

\section{Statistical Analysis}

Descriptive analysis was carried out by Excel 2013. A descriptive analysis of documented interventions was performed to evaluate the acceptance rate of pharmacist interventions by physicians to sort out accepted interventions by category, and to conduct cost analysis of accepted interventions in 2013. Statistical analysis was carried out by GraphPad Prism 7. Fisher's exact test was used to compare acceptance rate between each year and 2013, the year with the highest acceptance rate.

\section{RESULTS}

One thousand two hundred and seventy-five interventions were documented for the study period. The number of interventions varied each year. The lowest number of interventions was recorded in 2008; the highest number of interventions was documented in 2009. In 2008, the year when the clinical pharmacy service was initiated in the critical care unit, interventions were recorded only between August 1 and 
December 31 and thus resulted in the lowest number of interventions. The physician acceptance rate increased each year from the lowest acceptance rate in 2008 to the highest acceptance rate in 2013. Fisher's exact test demonstrated that the acceptance rate in 2013 was statistically significantly higher for 2008, 2009, 2010, and 2012. (Appendix 1) The overall acceptance rate for all documented interventions in the CCU for the study period was $56 \%$ (Table 1 \& Figure 1 ).

The toxicity/adverse drug reactions category had the highest total acceptance rate and the hospital protocol compliance category had the lowest overall acceptance rate (Table 2 \& Figure 2). The three most common types of documented interventions were in the undertreated, drug selection, and over/underdose categories. The top three types of interventions accounted for $75 \%$ of all documented interventions. Among these three categories, interventions in the drug selection category had the highest acceptance rate (Table 2 \& Figure 2).

Potential cost saving and cost avoidance were estimated using 75 out of 166 accepted interventions in 2013 (Table 1). Ten of these interventions were used to calculate both cost saving and cost avoidance (Table $3 \& 4$ ). Potential cost saving was based on the overall cost saving for each medication that was discontinued or resulted in dose reduction (Table 3 ). The total cost saving for the selected interventions in the CCU for the study period was $\$ 432$ (Table 3). Potential cost avoidance was based on the overall cost avoidance for selected interventions which potentially prevented unfavorable clinical events documented in medical literature (Table 4). ${ }^{18-25}$ Prevention of allergic reactions had the lowest cost avoidance, and sepsis or septic shock prevention had the highest cost avoidance (Table $4)$. For the selected interventions with available medical references, the overall cost avoidance was $\$ 400,598-\$ 412,225$ (Table 4). Potential cost avoidance for interventions where cost could not be found in the medical literature was calculated separately and amounted to $\$ 52,741.36-\$ 56,102.62$ (Table 5). Sum of the total cost avoidance in table 4 and the overall cost avoidance in table 5 was $\$ 453,339.36-\$ 468,327.62$.

\section{Discussion}

In our study, the overall acceptance rate by physicians (56\%) falls within the range of the acceptance rate reported in the literature. Viktil's study is a literature review which evaluated the effects of pharmacist interventions on drug-related problems and clinical outcomes and the acceptance rate by the prescriber. In that study, the prescriber acceptance rate in the hospital and community pharmacy settings ranged between $41 \%$ to $98 \%$. Prescriber acceptance rate in hospital setting was $89 \%-98 \% .{ }^{36}$ Although reported range in Viktil's article is wide, this could be due to various factors affecting the acceptance rate of pharmacist-recommended interventions. For example, several studies reported pharmacists' participation in hospital medical rounds as one of the factors that helped to increase acceptance rate. In 2007, Kopp et al. reported that $80 \%$ of accepted interventions made by a critical care pharmacist in the surgical ICU were made during patient care rounds and chartreview activities rather than during pharmacist-entered physician orders into the computer. ${ }^{14}$ Pedersen et al. reported that the number of clinical pharmacists attending medical rounds was $30.4 \%$ in 2001 and increased to $51.9 \%$ in $2013 .{ }^{15,} 37$ Although the overall percentage of pharmacists attending rounds with physicians is low, the percentage is higher in intensive care units. In 2004, MacLaren et al. evaluated clinical pharmacy services in ICUs via survey to the pharmacy directors. Responders reported that in their institutions, $62.2 \%$ of ICUs provided direct clinical pharmacy activities and pharmacists involved in these activities attended rounds $4.4 \pm 1.5$ days per week. $^{38}$

Our study demonstrates an increase in the acceptance rate of pharmacist-initiated recommendations by physicians over the five-year period. Similar findings were reported in the study conducted by Packard et al. who reported an increase in the acceptance rate for interventions recommended by pharmacy students from 2008 to $2013 .{ }^{39}$ Acceptance rate in 2013 was statistically significantly higher for 2008, 2009, 2010, and 2012. Although acceptance rate in 2013 was not statistically significantly higher for 2011, this could be possibly due to smaller number of interventions in year 2011 with slightly higher acceptance rate than in previous years. Furthermore, pvalue for 2011 vs 2013 was 0.0528, which suggests that it almost reached statistical significance.

Although there was a fewer number of recommended interventions in the toxicity/ADRs category, we hypothesize that the highest acceptance rate was due to the desire to enhance patient safety by avoiding significant adverse events. The acceptance rate in the toxicity/ADRs category is consistent with the results reported by Anderegg et al. study conducted in a tertiary hospital. ${ }^{40}$ Although the overall acceptance rate in compliance with hospital protocols category was low, annual acceptance rate in this category increased over the study period. Ongoing persistence on the part of the pharmacist in creating awareness of these protocols might have led to the yearly increase in acceptance rate. The undertreated category had the highest number of documented interventions. However, the rate of acceptance minimally increased over the study period. We concluded, similarly to Anderegg et al., that some of the pharmacist-recommended interventions in the CCU included medical conditions outside the primary reason for the admission and may be viewed by physicians as not being an immediate concern for the current admission. ${ }^{40}$ In 2006, Prosser et al. reported that hospital physicians prefer not to interfere with the prescription of the patient's primary care physician when patients are hospitalized. ${ }^{41}$ 
Pharmacist interventions could potentially result in positive economic outcomes. Evaluation of cost saving and cost avoidance is essential to assess the economic benefit of a pharmacist's clinical interventions. Kopp et al. reported that when a pharmacist in a surgical intensive care unit participated in medical rounds or chart review, approximately $\$ 80,000$ to $\$ 110,000$ of cost avoidance was reported in each activity and $\$ 160,000$ to $\$ 220,000$ of cost avoidance for both activities. ${ }^{14} \mathrm{~A}$ systematic review of 126 studies in inpatient $(n=59)$ and outpatient $(n=67)$ settings conducted by Chisholm-Burns et al. examined the economic effect of pharmacist-provided direct patient care on health outcomes in the United States. Among 20 studies, the major economic benefit came from the decreased length of stay (LOS), lower drug cost, and avoidance of potential unfavorable clinical events. This study demonstrated that the economic benefit per patient ranged between $\$ 145$ and $\$ 3,768 .{ }^{42}$

As noted previously, decreased length of stay is one of the major factors contributing to the economic benefit of the pharmacist interventions. This fact suggests that the increased LOS due to ADE can significantly contribute to the economic loss for the hospital. For example, Bates et al. showed that preventable ADEs, which mostly occurs during ordering and administration stages, increase the average hospital stay by 2.2 days with an associated total cost of $\$ 3,244 .^{34}$

The annual cost attributable to preventable ADEs for a 700-bed teaching hospital was estimated to be $\$ 2.8$ million. ${ }^{34}$ Therefore, clinical pharmacists can play a major role in reducing the economic loss associated with increased LOS due to the preventable ADEs.

Economic analysis of interventions or service outcomes requires a comprehensive measure of economic costs. ${ }^{42}$ Although in our study analysis of pharmacist interventions for one year time period was performed, since economic gain was difficult to be quantified with certainty for some interventions either due to missing documented information or lack of supporting literature, evaluated clinical interventions had economic benefit by either drug cost reduction or potential prevention of adverse clinical events that could result in total increase in medical care cost. Cost avoidance was higher than cost saving. While cost saving only reflects price of medications, cost avoidance accounts for overall management of adverse clinical outcomes. However, since the year with the highest acceptance rate was selected to evaluate economic benefit, it might introduce bias.

Complete assessment of economic benefit associated with pharmacist interventions should also take into consideration the cost associated with hiring a clinical pharmacist. In this study, there was no expenditure to the medical institution associated with hiring a clinical pharmacist since the pharmacist's salary and benefits were paid by an academic institution. Furthermore, the amount of time spent by the pharmacist to implement new clinical service was not documented. As a result, the pharmacist's salary, time, and the benefit versus cost ratio were not included in our study for the cost analysis. At other institutions, the expense associated with implementing a new clinical pharmacy service could be offset by economic savings obtained through pharmacist's interventions. For example, in a systematic review which evaluated economic benefit of clinical pharmacy service from fifty-nine studies between 1996 and 2000, Schumock et al. reported benefit versus cost ratio to be $4: 1$, a hospital saving up to $\$ 4$ for every $\$ 1$ invested in clinical pharmacy. ${ }^{43}$ In another systemic review from three studies between 2006 and 2010, Touchette et al. reported benefit versus cost ratio ranges from 1.05:1 to $25.95: 1$, a hospital saving ranges as little as $\$ 1.05$ to $\$ 25.95$ for every \$1 invested in clinical pharmacy. ${ }^{44}$ The broad range of the benefit versus cost ratio can be due to a number of clinical pharmacists required per institution, the pharmacist hiring salary, and pharmacist time spent on interventions might vary in each institution.

The study described here is unique since it evaluated interventions made by a single clinical pharmacist from the beginning of their service in the critical care unit. Furthermore, this study is distinctive as one of few studies which analyzed the acceptance rate and cost saving of the pharmacist interventions in the critical care setting in the rural hospital.

No precise measure of the collaborative relationship between the clinical pharmacist and physicians was completed. However, increase in the accepted interventions from 20082013 suggests that the development and maturation of the interprofessional relationships helped to improve the acceptance rate of the pharmacist interventions.

Our study has a number of limitations. Our study was conducted in the critical care unit, and therefore interventions may vary in other types of intensive care units. Also, due to the retrospective nature of the study, response by physicians could have occurred with or without the written recommendation by the pharmacist. Also, the analysis of economic benefit for selected interventions within a one year time instead of the five-year time frame was completed. The overall cost saving and cost avoidance would probably be higher if all interventions over 5 year study period were accounted in this analysis. Furthermore, since an external reviewer did not independently evaluate economic benefit, there is a chance for overinflated costs. Another limitation of our study is the use of the modified method for analyzing cost avoidance for the pharmacist interventions that lack literature references. In Saokawe and Nesbit's studies, a panel which consisted of several clinical pharmacists was used to assign the probability of preventable ADE for each pharmacist intervention. In our study, only one 
clinical pharmacist was available at the time of this project and the likelihood of preventable ADE was assigned by a research student after completion of data collection and during data analysis to minimize the investigator bias. It is possible that the probability of preventable ADE for the pharmacist interventions calculated in this study may differ from the probability of preventable ADE if it was calculated by the panel of clinical pharmacists.

Another limitation of our study is a lack of assessment of collaboration between a physician and a pharmacist and how it impacted physician acceptance rate. In the future, a PhysicianPharmacist Collaboration Instrument (PPCI) could be utilized to measure a degree of physician-pharmacist collaboration and its impact on the acceptance of interventions. ${ }^{5}$ Lastly, the major limitation of our study is mostly using descriptive analysis with minimal statistical analysis of found data. Prior to initiation of new clinical pharmacy service in the CCU, pharmacist interventions and the amount of time spent for each pharmacist intervention was not documented. If this data was available, several statistical analysis such as the student's unpaired t-test and benefit versus cost ratio could be conducted to assess whether the implementation of the new clinical pharmacy service significantly increased overall number of the pharmacist's interventions and acceptance rate by physicians, and cost saving to the institution. However, there are some descriptive publications focusing on pharmacist interventions; one such study is by Olson et al. ${ }^{45}$

\section{CONCLUSION}

This study differs from currently available literature on clinical pharmacist interventions in that it analyzed the acceptance rate and cost-benefit of the pharmacist interventions in the critical care setting in the rural hospital. Physician acceptance rate of pharmacist-recommended interventions in the critical care unit at White County Medical Center/Unity Health in Arkansas gradually increased over the 5-year period following implementation of a new clinical pharmacist service. Pharmacist's ongoing effort in building rapport with the CCU nursing director, nursing personnel, and physicians at WCMC might have helped to promote the implementation of the recommendations. Furthermore, clinical pharmacist expertise in managing drug regimens for the patients to minimize preventable ADEs might enable to support and guide the interdisciplinary team in delivering optimal therapeutic patient care. A one-year analysis of potential cost saving and cost avoidance of pharmacist interventions demonstrated a positive economic outcome based on current medical cost. This can be attractive to a health-system organization and may help to justify the cost of hiring a clinical pharmacist. Clinical pharmacist interventions may improve patient outcomes and provide potential economic benefit for the institution.
Acknowledgements: The authors would like to thank William Jerrod Cusick, Pharm.D. for his assistance with data collection and initial draft of the manuscript, Jordan Carmack, Pharm.D. and Timothy Mark Egbuka, Pharm. D. for their assistance with data collection, Jean Anne Mire, B.S.Pharm., M.B.A. for her assistance with the data analysis, and White County Medical Center/Unity Health for their assistance and support of this study.

\section{References}

1. Kim Y, Schepers G. Pharmacist intervention documentation in US health care systems. Hosp Pharm. 2003; 38(12):1141-7.

2. American Society of Hospital Pharmacists. ASHP statement on pharmaceutical care. Am J Hosp Pharm. 1993; 50:1720-3.

3. Preslaski CR, Lat I, MacLaren R, Poston J. Pharmacist contributions as members of the multidisciplinary ICU team. Chest. 2013; 144(5):1687-95.

4. Yarnall KSH, $\varnothing$ stbye T, Krause KM et al. Family physicians as team leaders: "time" to share the care. Prev Chronic Dis. 2009; 6(2):A59. http://www.cdc.gov/pcd/issues/2009/apr/08_0023.h tm. (accessed 2009 June 10).

5. Zillich AJ, Doucette WR, Carter BL, Kreiter CD. Development and initial validation of an instrument to measure physician-pharmacist collaboration from the physician perspective. Value Health. 2005; 8(1):59-66.

6. Borenstein JE, Graber G, Saltiel E, et al. Physicianpharmacist comanagement of hypertension: a randomized, comparative trial. Pharmacotherapy. 2003; 23:209-16.

7. Gattis WA, Hasselblad V, Whellan DJ, et al. Reduction in heart failure events by the addition of a clinical pharmacist to the heart failure management team: results of the Pharmacist in Heart Failure Assessment Recommendation and Monitoring (PHARM) Study. Arch Intern Med. 1999; 159:1939-45.

8. Chiquette $\mathrm{E}$, Amato MG, Bussey HI. Comparison of an anticoagulation clinic with usual medical care: anticoagulation control, patient outcomes, and health care costs. Arch Intern Med. 1998; 158:1641-7.

9. Rudis MI, Brandl KM. Position paper on critical care pharmacy services. Society of critical care medicine and the American College of Clinical Pharmacy task force on critical care pharmacy services. Crit Care Med. 2000; 28(11):3746-50. 
10. Brilli RJ, Spevetz A, Branson RD et al. Critical care delivery in the intensive care unit: defining clinical roles and the best practice model. Crit Care Med. 2001; 29(10):2007-19.

11. Chisholm-Burns MA, Graff Zivin JS, Lee JK et al. US pharmacists' effect as team members on patient care: Systematic review and meta-analyses. Med Care. 2010; 48:923-33.

12. Leape LL, Cullen DJ, Clapp MD et al. Pharmacist participation on physician rounds and adverse drug events in the intensive care unit. JAMA. 1999; 282(3):267-70.

13. Kucukarslan SN, Peters M, Mlynarek M. Pharmacists on rounding teams reduce preventable adverse drug events in hospital general medicine units. Arch Intern Med. 2003; 163:2014-18.

14. Kopp BJ, Mrsan M, Erstad BL, Duby JJ. Cost implications of and potential adverse events prevented by interventions of a critical care pharmacist. Am J Health Syst Pharm. 2007; 64(23):2483-87.

15. Pedersen CA, Schneider PJ, Scheckelholl DJ. ASHP national survey of pharmacy practice in hospital settings: Prescribing and transcribing-2013. Am J Health Syst Pharm. 2013; 71:924-42.

16. Thrasher K, O'Connor SK, Joyner PU. Rural Health in Pharmacy Curricula. Am J Pharm Educ. 2012;76(9):180.

17. ASHP Guidelines on a Standardized Method for Pharmaceutical Care. In: Deffenbaugh J, editor. Best Practices for Health-system Pharmacy. Bethesda, MD: American Society of Health System Pharmacists; 1996;p. 109-11;

18. National Coordinating Council for Medication Error Reporting and Prevention (NCC MERP). Types of Medication Errors. Available from: http://www.nccmerp.org/types-medication-errors [Last accessed on 2018]

19. Westerlund T, Almarsdóttir AB, Melander A. Drugrelated problems and pharmacy interventions in community practice. Int J Pharm Pract. 1999;7(1):4050.;

20. Pharmaceutical Care Network Europe. DRPclassification V6.2. Available from: http://www.pcne.org/upload/files/11 PCNE classific ation V6-2.pdf [Last accessed on 2018]
21. Mutnick AH, Sterba KJ, Peroutka JA et al. Cost savings and avoidance from clinical interventions. Am J Health-Syst Pharm. 1997; 54:392-96.

22. De Rijdt T, Willems L, Simoens S. Economic effects of clinical pharmacy interventions: A literature review. Am J Health-Syst Pharm. 2008; 65:1161-72.

23. Shepler BM. Cost savings associated with pharmacy student interventions during APPEs. Am J Pharm Educ. 2014; 78(4):71.

24. Lazar LD, Pletcher MJ, Coxson PG et al. Costeffectiveness of statin therapy for primary prevention in a low-cost statin era. Circulation. 2011; 124(2):14653.

25. Kang J, Mandsager P, Biddle AK, Weber DJ et al. Costeffectiveness analysis of active surveillance screening for MRSA in an academic hospital setting. Infect Control Hosp Epidemiol. 2012; 33(5):477-86.

26. Gillinov AM, Shi W, Rosen A et al. Cost of postoperative hyperglycemia in cardiac surgery patients. J Am Coll Cardiol. 2014; 63(12_S).

27. Gerson L. Cost-effectiveness analysis of management strategies for obscure GI bleeding. Gastrointest Endosc. 2008; 68:920-36.

28. Patel R, Badger N. The Impact of a pharmacist's participation on hospitalists' rounds. Hosp Pharm. 2010; 45(2):129-34.

29. Elixhauser A. (Agency for Healthcare Research and Quality), Friedman B. (Agency for Healthcare Research and Quality), Stranges E. (Thomson Reuters). Septicemia in U.S. Hospitals, 2009. HCUP Statistical Brief \#122. Agency for Healthcare Research and Quality, Rockville, MD. 2011; http://www.hcupus.ahrq.gov/reports/statbriefs/sb122.pdf

30. Saokaew S, Khaisombat N, Chaiyakunapruk N et al. Attributable cost and length of stay for patients with enoxaparin-associated bleeding. Value Health Reg Iss. 2012; 1:41-5.

31. Campbell AR, Nelson, LA, Elliott E, Hieber R, Sommi RW. Analysis of Cost Avoidance From Pharmacy Students' Clinical Interventions at a Psychiatric Hospital. Am J Pharm Educ. 2011;75(1):8.

32. Saokaew S, Maphanta S, Thangsomboon. P. Impact of pharmacist's interventions on cost of drug therapy in intensive care unit. Pharmacy Practice. 2009;7(2):8187. 
33. Nesbit TW, Shermock KM, Bobek MB et al., Implementation and pharmacoeconomic analysis of a clinical staff pharmacist practice model. Am J Health Syst Pharm. 2001;58(9):784-90.

34. Bates DW, Spell N, Cullen DJ et al. The costs of adverse drug events in hospitalized patients. JAMA. 1997; 277(4):307-11.

35. Consumer Price (CPI) Index Inflation Calculator. Bureau of Labor Statistics. United Stated Department of Labor. Available from:

https://www.bls.gov/data/inflation calculator.htm [Last accessed on 2018]

36. Viktil KK, Blix HS. The impact of clinical pharmacists on drug-related problems and clinical outcomes. Basic Clin Pharmacol Toxico. 2008; 102:275-80.

37. Pedersen CA, Schneider PJ, Santell JP. ASHP national survey of pharmacy practice in hospital settings: Prescribing and transcribing. Am J Health-Syst Pharm. 2001; 58:2251-66.

38. MacLaren R, Devlin JW, Martin SJ et al. Critical care pharmacy services in United States hospitals. Ann Pharmacother. 2006; 40(4):612-18.

39. Packard K, Gibu M, Teply R et al. Pharmacy student intervention acceptance on a cardiology rotation. Pharmacy Education. 2014; 14(1):64-69.

40. Anderegg SV, DeMik DE, Carter BL et al. Acceptance of recommendations by inpatient pharmacy case managers: unintended consequences of hospitalist and specialist care. Pharmacotherapy. 2013; 33(1):1121.

41. Prosser $\mathrm{H}$, Walley T. New drug prescribing by hospital doctors: the nature and meaning of knowledge. Soc Sci Med. 2006; 62:1565-78.

42. Chisholm-Burns MA, Graff Zivin JS, Lee JK et al. Economic effects of pharmacists on health outcomes in the United States: A systematic review. Am J Health-Syst Pharm. 2010; 67:1624-34.

43. Schumock GT, Butler MG, Meek PD et al. Evidence of the economic benefit of clinical pharmacy services: 1996-2000. Pharmacotherapy. 2003; 23(1):113-32.
44. Touchette DR, Doloresco F, Suda KJ, et al. Economic evaluations of clinical pharmacy services: 20062010. Pharmacotherapy. 2014;34(8):771-793.

45. Olson LM, Desai S, Soto ML, Namazifard S, Quelland AK, Erstad BL. (2005). Evaluation of pharmacists' interventions at a university teaching hospital. Canadian Journal of Hospital Pharmacy. 2005;58(1):20-25. 
Table 1 \& Figure 1.

Number of Recommended Interventions and Acceptance Percentage by Year

\begin{tabular}{|l|l|}
\hline Year & $\begin{array}{l}\text { Number of Accepted Interventions/Total Number of Interventions } \\
\text { (Percentage of Accepted Interventions) }\end{array}$ \\
\hline 2008 & $40 / 97(41 \%)$ \\
\hline 2009 & $158 / 349(45 \%)$ \\
\hline 2010 & $91 / 174(52 \%)$ \\
\hline 2011 & $86 / 141(61 \%)$ \\
\hline 2012 & $176 / 281(63 \%)$ \\
\hline 2013 & $166 / 233(71 \%)$ \\
\hline Total & $717 / 1275(56 \%)$ \\
\hline
\end{tabular}

$\% 2008-2013$

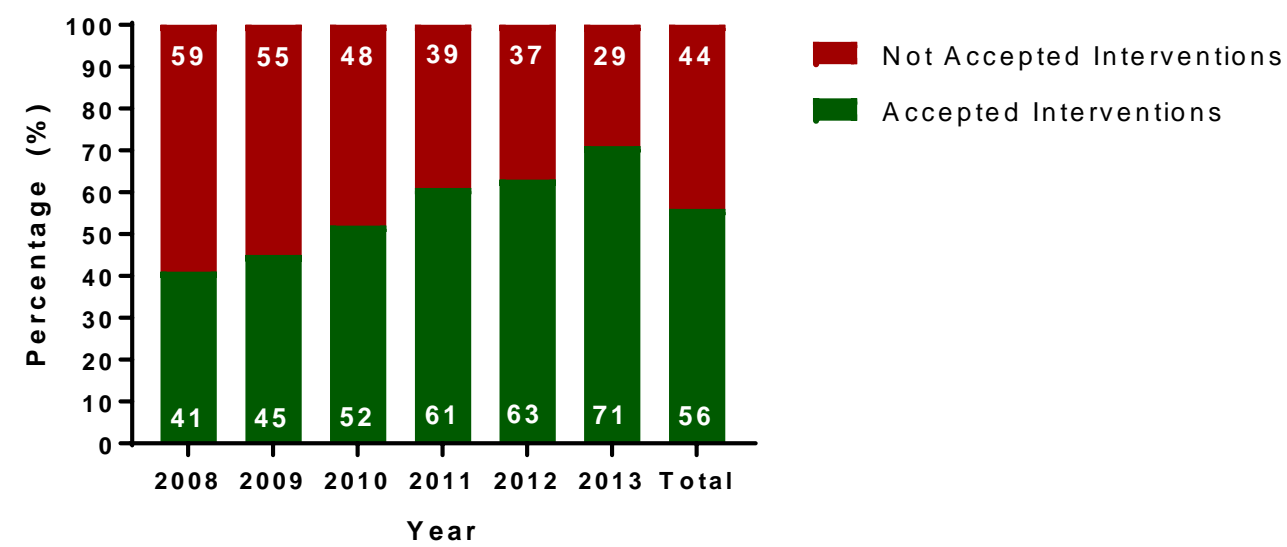

\begin{tabular}{|r|r|r|}
\hline & Accepted Interventions (\%) & Not Accepted Interventions (\%) \\
\hline 2008 & 41 & 59 \\
\hline 2009 & 45 & 55 \\
\hline 2010 & 52 & 48 \\
\hline 2011 & 61 & 39 \\
\hline 2012 & 63 & 37 \\
\hline 2013 & 71 & 29 \\
\hline Total & 56 & 44 \\
\hline
\end{tabular}


Table 2 \& Figure 2.

Types of Accepted Interventions by Category and Year ${ }^{\mathrm{a}}$

\begin{tabular}{|c|c|c|c|c|c|c|c|}
\hline \multirow{2}{*}{ Category } & \multicolumn{6}{|c|}{$\begin{array}{l}\text { Accepted/Total Number of Interventions by Year } \\
\text { (\% of Acceptance) }\end{array}$} & \multirow{2}{*}{$\begin{array}{l}\text { Accepted/Total Number o } \\
\text { Interventions Over Study } \\
\text { Period } \\
\text { (\% of Acceptance) }\end{array}$} \\
\hline & $\begin{array}{l}2008 \\
n(\%)\end{array}$ & $\begin{array}{l}2009 \\
\text { n (\%) }\end{array}$ & $\begin{array}{l}2010 \\
n(\%)\end{array}$ & $\begin{array}{l}2011 \\
n(\%)\end{array}$ & $\begin{array}{l}2012 \\
n(\%)\end{array}$ & $\begin{array}{l}2013 \\
n(\%)\end{array}$ & \\
\hline Toxicity/ADRs ${ }^{a}$ & 0 (NA) & $2 / 2(100)$ & 0 (NA) & 0 (NA) & $\begin{array}{l}1 / 1 \\
(100)\end{array}$ & $\begin{array}{l}2 / 2 \\
(100)\end{array}$ & $5 / 5(100)$ \\
\hline Education & 0 (NA) & $6 / 6(100)$ & $\begin{array}{l}5 / 5 \\
(100)\end{array}$ & $4 / 5(80)$ & $\begin{array}{l}3 / 3 \\
(100)\end{array}$ & 0 (NA) & $18 / 19(95)$ \\
\hline Monitoring & $3 / 8(38)$ & $\begin{array}{l}14 / 22 \\
(64) \\
\end{array}$ & $\begin{array}{l}5 / 10 \\
(50)\end{array}$ & $6 / 8(75)$ & $\begin{array}{l}12 / 15 \\
(80)\end{array}$ & $\begin{array}{l}18 / 23 \\
(78)\end{array}$ & $58 / 86(67)$ \\
\hline Not Classifiable ${ }^{b}$ & $3 / 9(33)$ & $5 / 8(63)$ & $3 / 8(38)$ & $\begin{array}{l}3 / 3 \\
(100)\end{array}$ & $3 / 4(75)$ & $\begin{array}{l}7 / 7 \\
(100)\end{array}$ & $24 / 39(62)$ \\
\hline Drug Selection & $3 / 9(33)$ & $\begin{array}{l}30 / 69 \\
(43)\end{array}$ & $\begin{array}{l}8 / 13 \\
(62)\end{array}$ & $\begin{array}{l}20 / 35 \\
(57)\end{array}$ & $\begin{array}{l}52 / 82 \\
(63)\end{array}$ & $\begin{array}{l}65 / 82 \\
(79)\end{array}$ & $178 / 290(61)$ \\
\hline Undertreated & $\begin{array}{l}25 / 44 \\
(57)\end{array}$ & $\begin{array}{l}62 / 113 \\
(55)\end{array}$ & $\begin{array}{l}41 / 73 \\
(56)\end{array}$ & $\begin{array}{l}23 / 39 \\
(59)\end{array}$ & $\begin{array}{l}50 / 84 \\
(60)\end{array}$ & $\begin{array}{l}22 / 39 \\
(56)\end{array}$ & $223 / 392(57)$ \\
\hline Over or Underdose & $2 / 8(25)$ & $\begin{array}{l}22 / 66 \\
(33) \\
\end{array}$ & $\begin{array}{l}22 / 37 \\
(59) \\
\end{array}$ & $\begin{array}{l}25 / 43 \\
(58) \\
\end{array}$ & $\begin{array}{l}45 / 74 \\
(61)\end{array}$ & $\begin{array}{l}28 / 50 \\
(56)\end{array}$ & $144 / 278(52)$ \\
\hline $\begin{array}{l}\text { Compliance with } \\
\text { hospital protocols }\end{array}$ & $\begin{array}{l}4 / 19 \\
(21)\end{array}$ & $\begin{array}{l}17 / 63 \\
(27)\end{array}$ & $\begin{array}{l}7 / 28 \\
(25)\end{array}$ & $5 / 8(63)$ & $\begin{array}{l}10 / 18 \\
(56)\end{array}$ & $\begin{array}{l}24 / 30 \\
(80)\end{array}$ & $67 / 166(40)$ \\
\hline
\end{tabular}

${ }^{\mathrm{a}} \mathrm{ADRs}=$ Adverse Drug Reactions

${ }^{b}$ Not Classifiable = Interventions that do not fall into any of the following categories: drug selection, over or underdose, monitoring, compliance with hospital protocols, undertreated, education, toxicity/adverse drug reactions 
Toxic ity

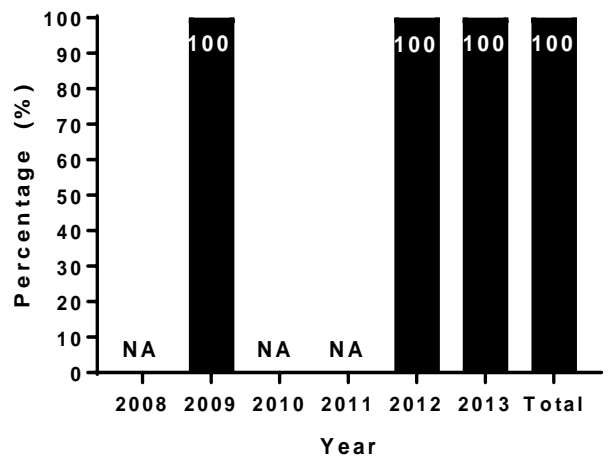

*NA: No intervention in this category

Monitoring
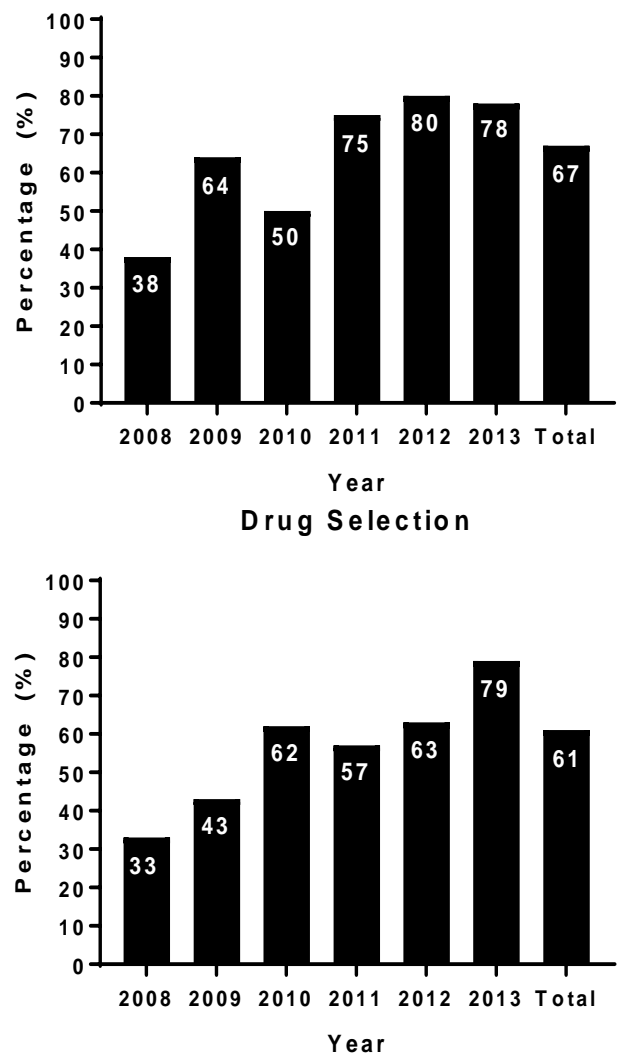

Over or Underdose

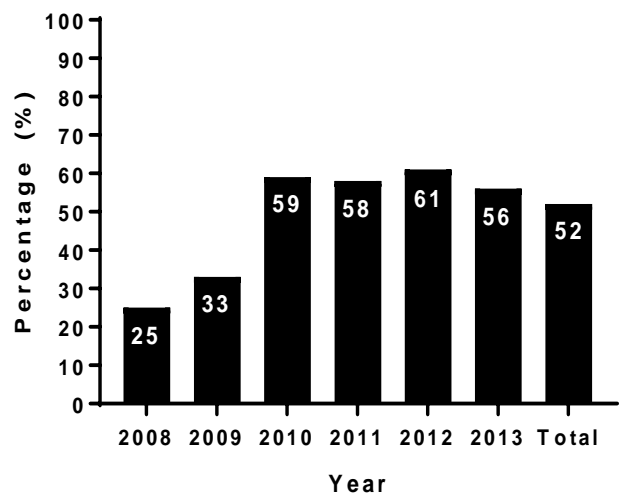

Education

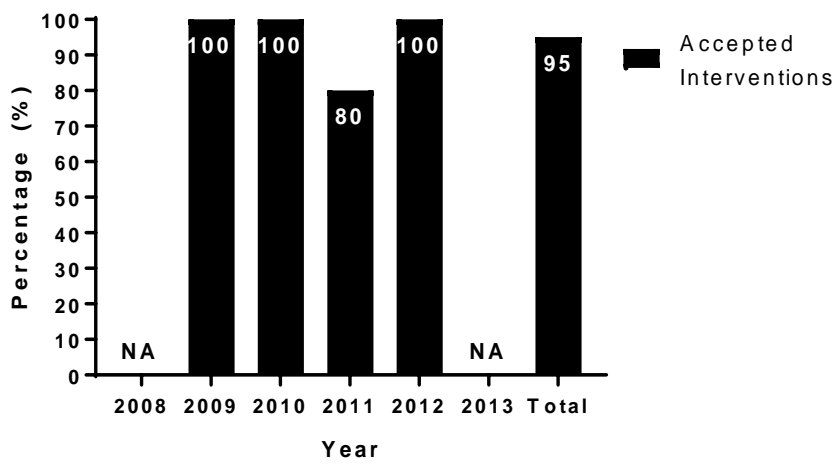

${ }^{*} \mathrm{NA}$ : No intervention in this category

Not Classifiable
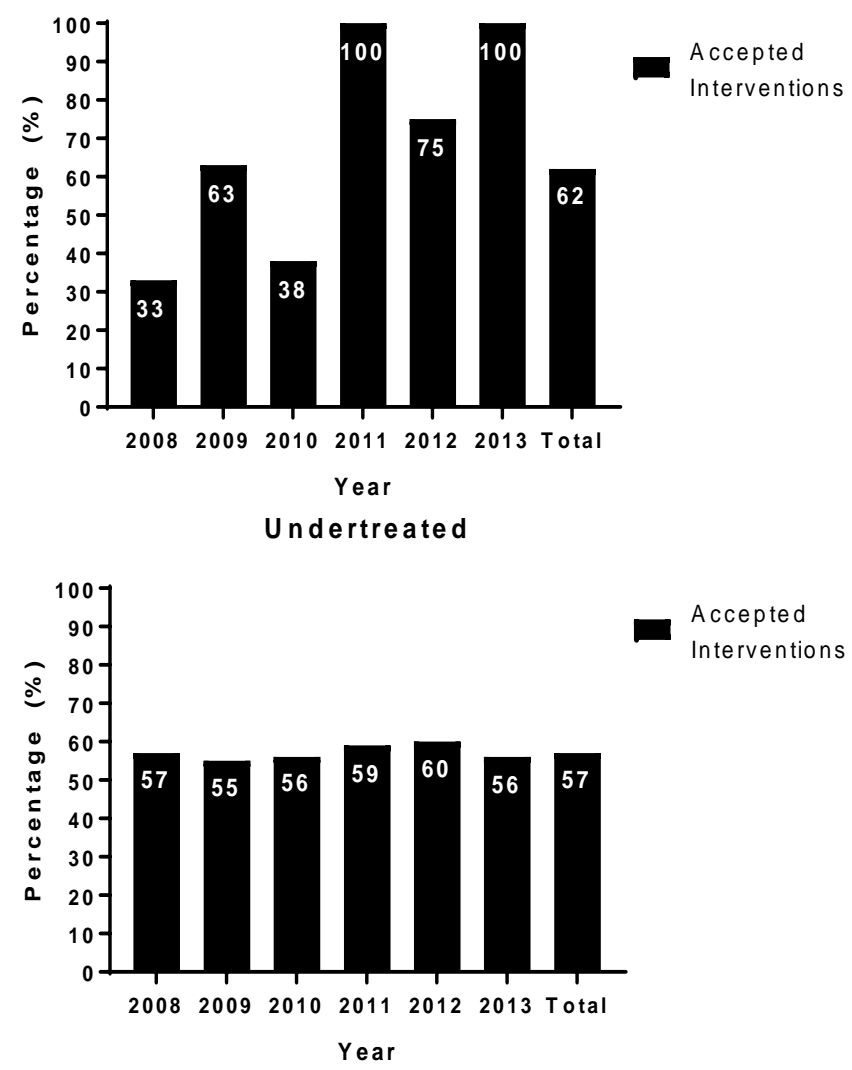

Compliance with hospital protocols

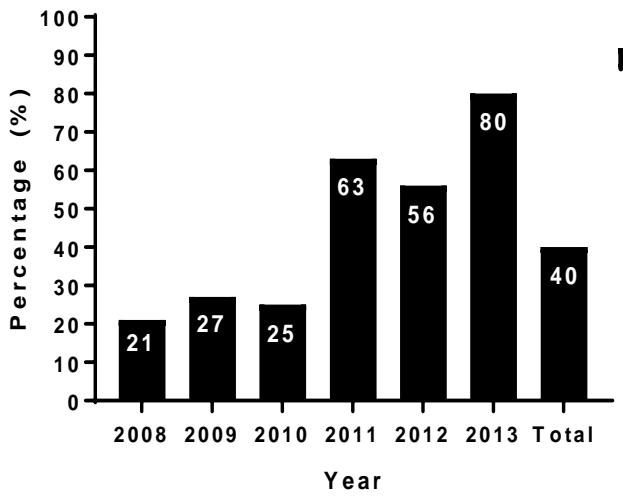


Table 3.

Outcome Measure Examples of Cost Reduction per Daily Dose for $2013^{\mathrm{a}}$

\begin{tabular}{|l|l|l|}
\hline Selected Examples of Interventions & $\begin{array}{l}\text { Number of Accepted } \\
\text { Interventions }\end{array}$ & $\begin{array}{l}\text { Estimated Cost } \\
\text { Saving,c }\end{array}$ \\
\hline $\begin{array}{l}\text { Discontinue famotidine } 20 \mathrm{mg} \text { intravenously BID for patients who are } \\
\text { on pantoprazole }\end{array}$ & 10 & $\$ 29$ \\
\hline $\begin{array}{l}\text { Discontinue azithromycin } 500 \mathrm{mg} \text { intravenously for patients who are } \\
\text { on levofloxacin }\end{array}$ & 4 & $\$ 29$ \\
\hline $\begin{array}{l}\text { Change enoxaparin 40 mg subcutaneously QD to 30 mg } \\
\text { subcutaneously QD for DVT prophylaxis due to decline in renal } \\
\text { function }\end{array}$ & 5 & $\$ 33$ \\
\hline $\begin{array}{l}\text { Discontinue enoxaparin 40 mg subcutaneously QD in patients with } \\
\text { low platelet count }\end{array}$ & 6 & $\$ 158$ \\
\hline $\begin{array}{l}\text { Discontinue ceftriaxone 2 g intravenously BID in a patient on } \\
\text { piperacillin/tazobactam }\end{array}$ & 1 & $\$ 183$ \\
\hline Total cost saving for accepted interventions & $26^{*}$ & $\$ 432$ \\
\hline
\end{tabular}

${ }^{a} B I D=$ twice daily, QD = once daily, DVT = deep venous thrombosis

${ }^{b}$ Drug cost saving per dose is based on average wholesale price (AWP)

${ }^{\mathrm{C}}$ Total cost saving $=$ drug cost saving per dose $\mathrm{x}$ number of accepted interventions

*10 of these interventions were used to calculate both cost saving and cost avoidance 
Table 4.

Estimated Cost Avoidance Examples for Prevention of Potential Adverse Clinical Outcomes for $2013^{\mathrm{a}}$

\begin{tabular}{|c|c|c|c|c|}
\hline $\begin{array}{l}\text { Selected Examples of } \\
\text { Interventions }\end{array}$ & $\begin{array}{l}\text { Clinical Rationale } \\
\text { for } \\
\text { Recommendation }\end{array}$ & $\begin{array}{l}\text { Literature Source Used } \\
\text { for Cost Avoidance } \\
\text { Calculations }\end{array}$ & $\begin{array}{l}\text { Number of } \\
\text { Accepted } \\
\text { Interventions }\end{array}$ & $\begin{array}{l}\text { Estimated Cost } \\
\text { Avoidance } \\
\text { (Cost } \\
\text { avoidance per } \\
\text { intervention) }{ }^{b, c}\end{array}$ \\
\hline $\begin{array}{l}\text { Update patients' } \\
\text { allergies record }\end{array}$ & $\begin{array}{l}\text { Prevent allergic } \\
\text { reaction }\end{array}$ & $\begin{array}{l}\text { 23. Shepler BM. Cost } \\
\text { savings associated with } \\
\text { pharmacy student } \\
\text { interventions during } \\
\text { APPEs. Am J Pharm } \\
\text { Educ. } 2014 ; 78(4): 71 .\end{array}$ & 8 & $\$ 8,720(\$ 1,090)$ \\
\hline $\begin{array}{l}\text { Change simvastatin } 80 \\
\text { mg by mouth QD to } 20 \\
\text { mg by mouth QD in a } \\
\text { patient on amiodarone }\end{array}$ & $\begin{array}{l}\text { Prevent } \\
\text { rhabdomyolysis }\end{array}$ & $\begin{array}{l}\text { 24. Lazar LD, Pletcher } \\
\text { MJ, Coxson PG et al. } \\
\text { Cost-effectiveness of } \\
\text { statin therapy for } \\
\text { primary prevention in a } \\
\text { low-cost statin era. } \\
\text { Circulation. } 2011 \text {; } \\
\text { 124(2):146-53. }\end{array}$ & 1 & $\$ 11,745(\$ 11,745)$ \\
\hline $\begin{array}{l}\text { Compliance with nasal } \\
\text { MRSA colonization } \\
\text { screening for newly } \\
\text { admitted patients }\end{array}$ & $\begin{array}{l}\text { Prevent MRSA } \\
\text { spread }\end{array}$ & $\begin{array}{l}\text { 25. Kang J, Mandsager P, } \\
\text { Biddle AK, Weber DJ et } \\
\text { al. Cost-effectiveness } \\
\text { analysis of active } \\
\text { surveillance screening } \\
\text { for MRSA in an } \\
\text { academic hospital } \\
\text { setting. Infect Control } \\
\text { Hosp Epidemiol. 2012; } \\
\text { 33(5):477-86. }\end{array}$ & 2 & $\$ 29,910(\$ 14,955)$ \\
\hline $\begin{array}{l}\text { Blood glucose } \\
\text { management to } \\
\text { maintain it between } \\
140-180 \mathrm{mg} / \mathrm{dL}\end{array}$ & $\begin{array}{l}\text { AACE and ADA } \\
\text { recommendation } \\
\text { for critically ill } \\
\text { patients in order } \\
\text { to reduce LOS in } \\
\text { ICU and improve } \\
\text { management of } \\
\text { infection } \\
\end{array}$ & $\begin{array}{l}\text { 26. Gillinov AM, Shi W, } \\
\text { Rosen A et al. Cost of } \\
\text { postoperative } \\
\text { hyperglycemia in cardiac } \\
\text { surgery patients. J Am } \\
\text { Coll Cardiol. 2014; } \\
63(12 \text { S). }\end{array}$ & 13 & $\$ 34,177(\$ 2,629)$ \\
\hline $\begin{array}{l}\text { Initiate stress ulcer } \\
\text { prophylaxis in patients } \\
\text { on mechanical } \\
\text { ventilation }\end{array}$ & $\begin{array}{l}\text { Prevent } \\
\text { gastrointestinal } \\
\text { bleeding }\end{array}$ & $\begin{array}{l}\text { 27. Gerson L. Cost- } \\
\text { effectiveness analysis of } \\
\text { management strategies } \\
\text { for obscure GI bleeding. } \\
\text { Gastrointest Endosc. } \\
\text { 2008; 68:920-36. }\end{array}$ & 3 & $\$ 40,956(\$ 13,652)$ \\
\hline $\begin{array}{l}\text { Initiate/adjust dose for } \\
\text { pharmacological DVT } \\
\text { prophylaxis and/or } \\
\text { initiate mechanical DVT } \\
\text { prophylaxis }\end{array}$ & Prevent DVT & $\begin{array}{l}\text { 28. Patel R, Badger } \mathrm{N} \text {. } \\
\text { The Impact of a } \\
\text { pharmacist's } \\
\text { participation on } \\
\text { hospitalists' rounds. } \\
\text { Hosp Pharm. 2010; } \\
\text { 45(2):129-34. }\end{array}$ & 11 & $\$ 66,000(\$ 6,000)$ \\
\hline
\end{tabular}




\begin{tabular}{|c|c|c|c|c|}
\hline $\begin{array}{l}\text { Modify antimicrobial } \\
\text { therapy to include } \\
\text { coverage for MDR } \\
\text { pathogens in patients } \\
\text { with infection and } \\
\text { declining clinical status }\end{array}$ & $\begin{array}{l}\text { Prevent sepsis } \\
\text { and/or septic } \\
\text { shock }\end{array}$ & $\begin{array}{l}\text { 29. Elixhauser A. } \\
\text { (Agency for Healthcare } \\
\text { Research and Quality), } \\
\text { Friedman B. (Agency for } \\
\text { Healthcare Research } \\
\text { and Quality), Stranges E. } \\
\text { (Thomson Reuters). } \\
\text { Septicemia in U.S. } \\
\text { Hospitals, 2009. HCUP } \\
\text { Statistical Brief \#122. } \\
\text { Agency for Healthcare } \\
\text { Research and Quality, } \\
\text { Rockville, MD. 2011; } \\
\text { http://www.hcup- } \\
\text { us.ahrq.gov/reports/stat } \\
\text { briefs/sb122.pdf }\end{array}$ & 10 & $\$ 185,000(\$ 18,500)$ \\
\hline $\begin{array}{l}\text { Discontinue enoxaparin } \\
\text { in patients with } \\
\text { consistently decreasing } \\
\text { platelet count or adjust } \\
\text { enoxaparin dose in } \\
\text { patients with renal } \\
\text { insufficiency }\end{array}$ & $\begin{array}{l}\text { Reduce risk of } \\
\text { bleeding }\end{array}$ & $\begin{array}{l}\text { 30. Saokaew S, } \\
\text { Khaisombat N, } \\
\text { Chaiyakunapruk N et al. } \\
\text { Attributable cost and } \\
\text { length of stay for } \\
\text { patients with } \\
\text { enoxaparin-associated } \\
\text { bleeding. Value Health } \\
\text { Reg Iss. } 2012 ; 1: 41-5 .\end{array}$ & 11 & $\begin{array}{l}\$ 24,090-\$ 35,717^{d} \\
(\$ 2,190-\$ 3,247)\end{array}$ \\
\hline Total cost & - & - & $59 *$ & $\$ 400,598-\$ 412,225^{\circ}$ \\
\hline
\end{tabular}

${ }^{\mathrm{a}} \mathrm{QD}=$ once daily, MRSA = methicillin-resistant Staphylococcus aureus, $\mathrm{AACE}=$ American Association of Clinical Endocrinologists, $A D A=$ American Diabetes Association, $L O S=$ length of stay, ICU = intensive care unit, DVT = deep venous thrombosis, MDR = multi-drug resistant

${ }^{b}$ Cost avoidance is based on the literature source

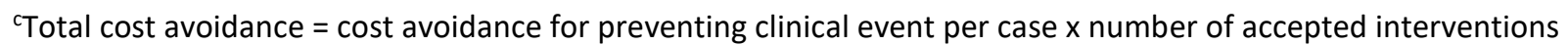

${ }^{\mathrm{d}}$ Range indicates cost for minor vs major bleeding

*10 of these interventions were used to calculate both cost saving and cost avoidance. 
Table 5.

Pharmacist Interventions Lacking Cost Avoidance Medical References

\begin{tabular}{|c|c|c|c|}
\hline Category & $\begin{array}{l}\text { Probability of preventable } \\
\text { Adverse Drug Events (ADE) } \\
\text { (Range: } 0 \text { to } 1 \text { ) }\end{array}$ & $\begin{array}{l}\text { Total Number of } \\
\text { Accepted } \\
\text { Interventions }\end{array}$ & $\begin{array}{l}\text { Calculated Total Cost } \\
\text { Avoidance Range }\end{array}$ \\
\hline Duplicate therapy & 0.1 (Duplicate therapy) & 30 & $\$ 21,324$ to $\$ 22,683$ \\
\hline $\begin{array}{l}\text { Over or Underdose and } \\
\text { Undertreated }\end{array}$ & $\begin{array}{l}0.1 \text { (Medication/dose } \\
\text { inadequate to produce } \\
\text { therapeutic effect or } \\
\text { incorrect schedule/route } \\
\text { with potential for } \\
\text { therapeutic } \\
\text { failure/toxicity) }\end{array}$ & 26 & $\$ 18,480.8$ to $\$ 19,658.6$ \\
\hline \multirow[t]{3}{*}{ Compliance/Drug Selection } & $\begin{array}{l}0.01 \text { (clarifications, } \\
\text { missing information) }\end{array}$ & 12 & $\$ 852.96$ to $\$ 907.32$ \\
\hline & $\begin{array}{l}0.1 \text { (Medication/dose } \\
\text { inadequate to produce } \\
\text { therapeutic effect) }\end{array}$ & 5 & $\$ 3,554$ to $\$ 3,780.5$ \\
\hline & $\begin{array}{l}0.4 \text { (no adjustment of } \\
\text { medication with renal } \\
\text { failure or other issues such } \\
\text { as hyperkalemia or } \\
\text { elevated trough level) }\end{array}$ & 3 & $\$ 8,529.6$ to $\$ 9,073.2$ \\
\hline Monitoring & $N / A^{a}$ & 15 & $N / A^{a}$ \\
\hline Total & - & - & $\$ 52,741.36$ to $\$ 56,102.62$ \\
\hline
\end{tabular}

${ }^{a} \mathrm{~N} / \mathrm{A}=$ Not Applicable (e.g., Pharmacist request to continuously monitor aPTT after heparin administration. In this case, patient may or may not have ADE and therefore, probability of ADE cannot be calculated)

Preventable ADE cost is \$4685 (Study period from Feb 1993 to July 1993 for Bates study), Preventable ADE cost after multiplying with Consumer Price Index (CPI) in August 2008 to December 2013 (5 Year Study Period):

August 2008: $\$ 4685$ (July 1993) x CPI = \$7108.16 \$7108

December 2013: $\$ 4685$ (July 1993) x CPI = \$7561.18 $\sim 7561$

(e.g., Total \# of interventions $X$ the probability of ADE $X$ the average cost of preventable ADE $=30 \times 0.1 \times 7108$ or $7561=$ \$21324 to \$22683) 
Appendix 1. Statistical Analysis of Acceptance Rate Over Study Period

2008 vs 2013

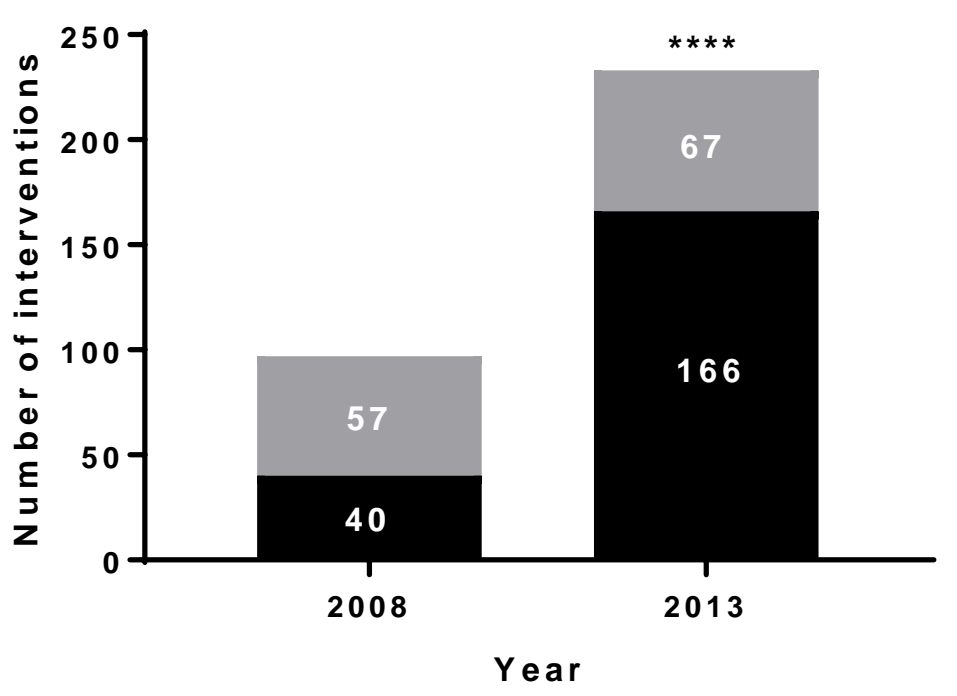

Not Accepted

Accepted

\begin{tabular}{|l|l|l|l|}
\hline & & & \\
\hline P value and statistical significance & & & \\
\hline Test & Fisher's exact test & & \\
\hline & & & \\
\hline P value & $<0.0001$ & & \\
\hline P value summary & $\star \star \star \star$ & & \\
\hline One- or two-sided & Two-sided & & \\
\hline Statistically significant $(P<0.05) ?$ & Yes & & \\
\hline & & & Not Accepted \\
\hline Data analyzed & Accepted & 57 & 97 \\
\hline 2008 & 40 & 67 & 233 \\
\hline 2013 & 166 & 124 & 330 \\
\hline Total & 206 & & \\
\hline
\end{tabular}


2009 vs 2013

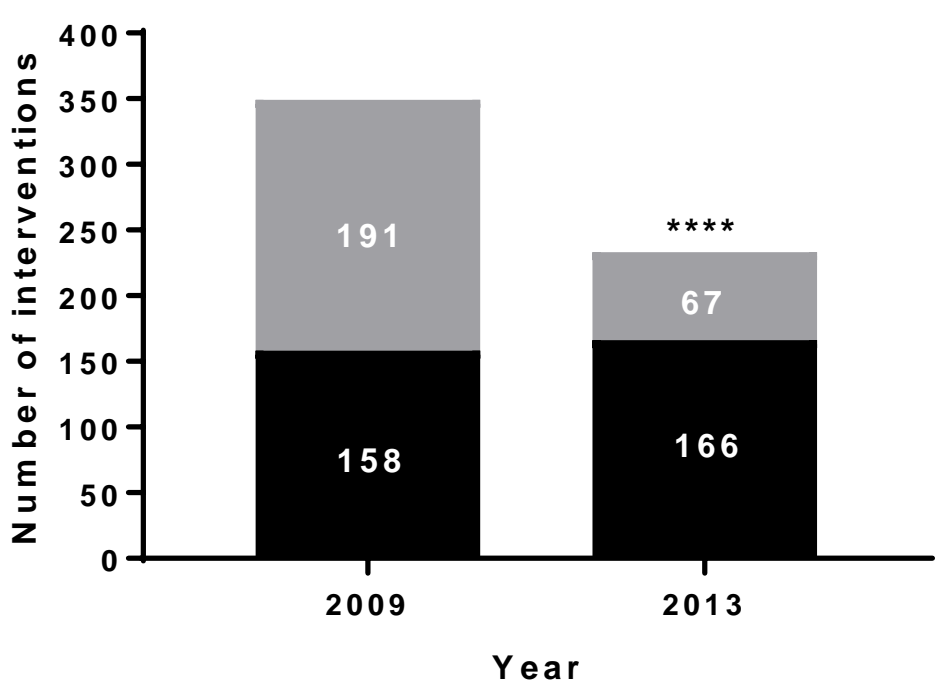

Not Accepted

Accepted

Year

\begin{tabular}{|c|c|c|c|}
\hline & & & \\
\hline \multicolumn{4}{|l|}{$\mathrm{P}$ value and statistical significance } \\
\hline Test & Fisher's exact test & & \\
\hline$P$ value & $<0.0001$ & & \\
\hline$P$ value summary & $\star \star \star \star ~$ & & \\
\hline One- or two-sided & Two-sided & & \\
\hline Statistically significant $(\mathrm{P}<0.05)$ ? & Yes & & \\
\hline Data analyzed & Accepted & Not Accepted & Total \\
\hline 2009 & 158 & 191 & 349 \\
\hline 2013 & 166 & 67 & 233 \\
\hline Total & 324 & 258 & 582 \\
\hline
\end{tabular}




\section{0 vs 2013}

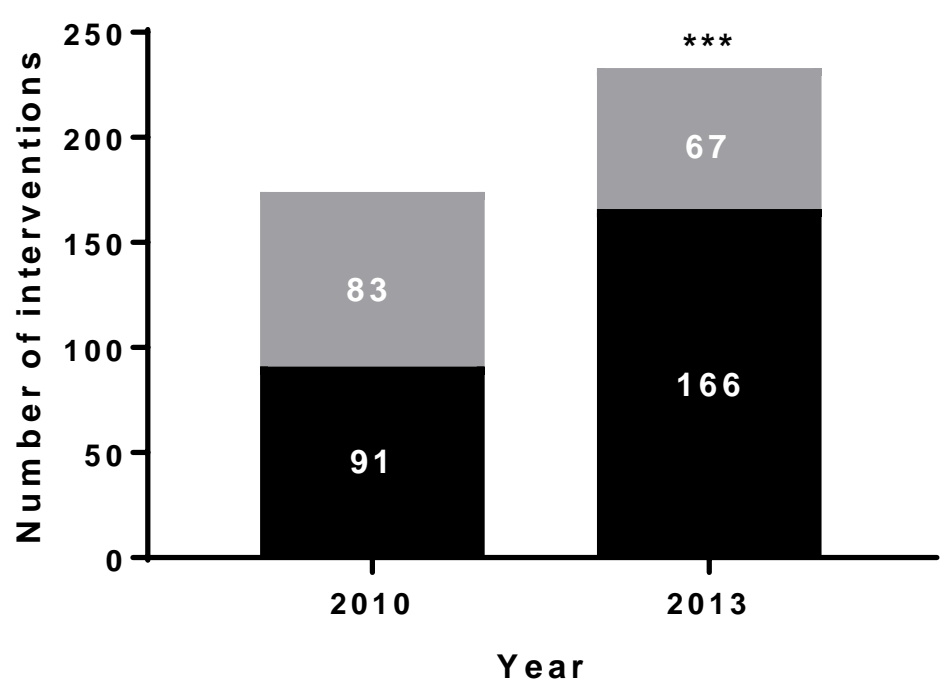

Not Accepted

Accepted

\begin{tabular}{|c|l|l|l|}
\hline & & & \\
\hline P value and statistical significance & & & \\
\hline Test & Fisher's exact test & & \\
\hline & & & \\
\hline P value & 0.0001 & & \\
\hline P value summary & $\star \star \star$ & & \\
\hline One- or two-sided & Two-sided & & \\
\hline Statistically significant $(P<0.05) ?$ & Yes & & \\
\hline & & & Not Accepted \\
\hline Data analyzed & Accepted & Total \\
\hline 2010 & 91 & 83 & 174 \\
\hline 2013 & 166 & 67 & 233 \\
\hline Total & 257 & 150 & 407 \\
\hline
\end{tabular}




\section{1 vs 2013}

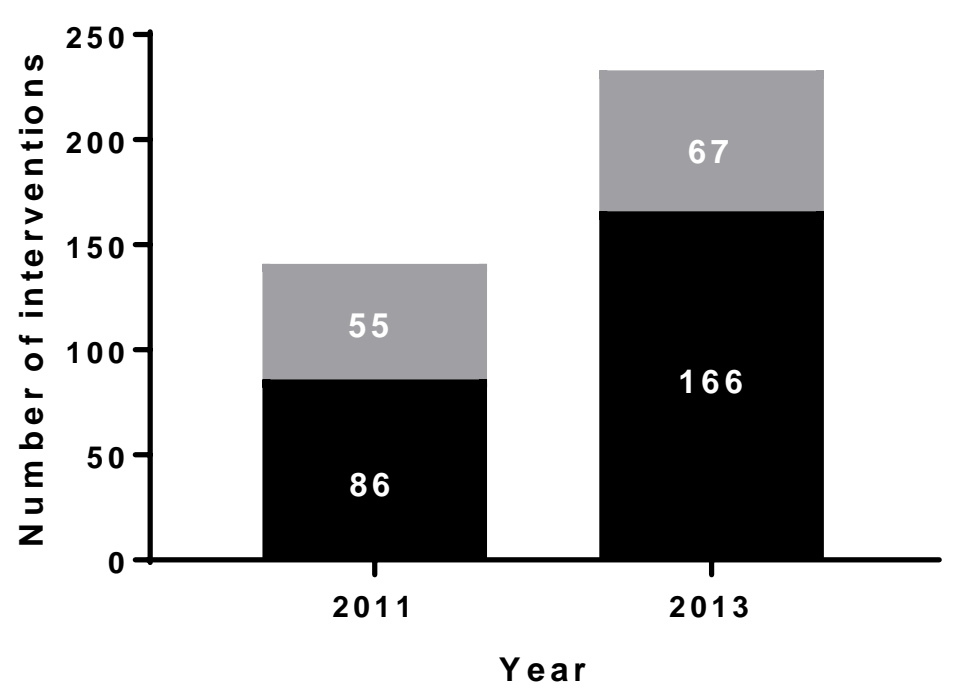

Not Accepted

A c cepted

\begin{tabular}{|c|l|l|l|}
\hline & & & \\
\hline P value and statistical significance & & & \\
\hline Test & Fisher's exact test & & \\
\hline & & & \\
\hline P value & 0.0528 & & \\
\hline P value summary & ns & & \\
\hline One- or two-sided & Two-sided & & \\
\hline Statistically significant $(P<0.05) ?$ & No & & \\
\hline & & & Notal \\
\hline Data analyzed & Accepted & Not Accepted & Th1 \\
\hline 2011 & 86 & 55 & 233 \\
\hline 2013 & 166 & 67 & 374 \\
\hline Total & 252 & 122 & \\
\hline
\end{tabular}


2012 vs 2013

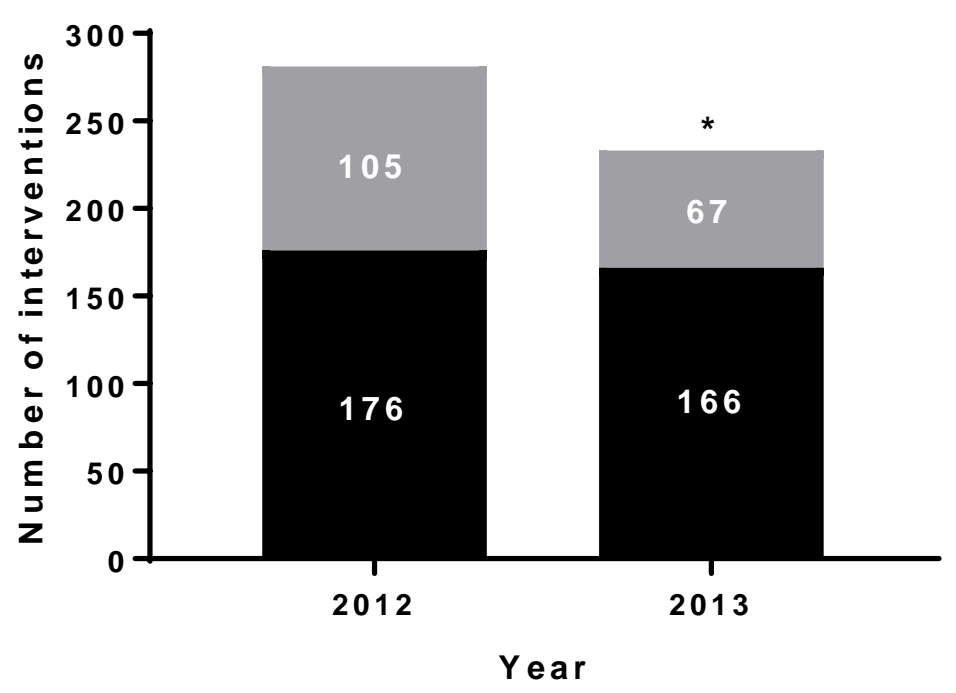

Not Accepted

- Accepted

\begin{tabular}{|l|l|l|l|}
\hline & & & \\
\hline P value and statistical significance & & & \\
\hline Test & Fisher's exact test & & \\
\hline & & & \\
\hline P value & 0.0485 & & \\
\hline P value summary & $\star$ & & \\
\hline One- or two-sided & Two-sided & & \\
\hline Statistically significant $(P<0.05) ?$ & Yes & & \\
\hline & & & Not Accepted \\
\hline Data analyzed & Accepted & 105 & 281 \\
\hline 2012 & 176 & 67 & 233 \\
\hline 2013 & 166 & 172 & 514 \\
\hline Total & 342 & & \\
\hline
\end{tabular}

